\title{
Job Stress and Burnout among Social Workers in the VUCA World of COVID-19 Pandemic
}

\author{
Gabriela Dima *, Luiza Meseșan Schmitz (D) and Marinela-Cristina Șimon
}

check for updates

Citation: Dima, G.; Meseșan Schmitz L.; Simon, M.-C. Job Stress and Burnout among Social Workers in the VUCA World of COVID-19 Pandemic. Sustainability 2021, 13, 7109. https:// doi.org/10.3390/su13137109

Academic Editors:

Emanuele Cannizzaro,

Tiziana Ramaci,

Massimiliano Barattucci and Fulvio Plescia

Received: 16 April 2021

Accepted: 15 June 2021

Published: 24 June 2021

Publisher's Note: MDPI stays neutral with regard to jurisdictional claims in published maps and institutional affiliations.

Copyright: (c) 2021 by the authors. Licensee MDPI, Basel, Switzerland. This article is an open access article distributed under the terms and conditions of the Creative Commons Attribution (CC BY) license (https:// creativecommons.org/licenses/by/ $4.0 /)$.
Faculty of Sociology and Communication, Transilvania University of Brasov, 500036 Brasov, Romania; luiza.mesesan@unitbv.ro (L.M.S.); marinela.simon@unitbv.ro (M.-C.S.)

* Correspondence: dima.gabriela@unitbv.ro

Abstract: This paper aimed to explore the changes posed by the new COVID-19 pandemic to the field of social work and its impact on social workers in terms of job stress and burnout in Romania. Two conceptual models were used to frame the discussion: the theoretical framework of VUCA (volatility, uncertainty, complexity, and ambiguity) to discuss the challenges that the unprecedented context of the COVID-19 pandemic has created for social workers; and the Job Demands and Resources model (JD-R) to understand job demands perceived as stressors and burnout. Based on convergent mixed methods, the study sample consisted of 83 social workers employed in statutory and private social services in Romania, from different areas of intervention. Results showed that social workers perceived a high level of job stress related to work during the pandemic, which was associated with higher levels of burnout in the areas of personal burnout (average score 55.9) and work-related burnout (average score 52.5). Client-related burnout was lower (average score 38.4), indicating that stress was generated mainly by organisational factors and work-related factors (workload, aligning to new legislative rules and decisions, inconsistency, instability, ambiguity of managerial decisions, and lack of clarity of working procedures) and less by client-related stressors (lack of direct contact with clients, risk of contamination, managing beneficiaries' fears, and difficulties related to technology). High job demands and limited job resources (managerial and supervisory support, financial resources, and recognition and reward) led to a high to very high level of work-related burnout for $15.7 \%$ and an upper-medium level for $44.2 \%$ of respondents. A group of $27.7 \%$ reported lower to medium levels of work-related burnout, while $14.5 \%$ had very low levels, managing to handle stress factors in a healthy manner. Study results pointed to the importance of organisational support and the development of a self-care plan that help to protect against job stress and burnout. Recommendations were made, putting forward the voice of fieldworkers and managers fostering initiatives and the application of sustainability-based measures and activities designed to deal with the challenges of the VUCA environment.

Keywords: COVID-19; social work/er; job stress; burnout; VUCA

\section{Introduction}

The world has changed and "no one prepared us for this", as was vividly expressed by one of the social workers. The COVID-19 pandemic has become a major public healthcare concern worldwide and has impacted the economy, environmental sustainability and social responsibility [1], as well as every aspect of human life [2]. Therefore, the COVID19 pandemic has caused not only serious health problems, which patients, healthcare professionals, and health systems around the world have tried to deal with, but also significant related social problems. Social isolation of vulnerable people (the elderly, people with disabilities, people with chronic diseases, etc.), restrictive measures imposed, teleworking, overcrowding of hospitals, and the closure of schools and kindergartens have created a general state of uncertainty, chaos, stress, and panic among the population [3-5]. This has heightened the role of the social work and medical systems during the COVID-19 
crisis, responding to inequalities and covering the most urgent social needs of vulnerable groups [6].

In Romania, after a long break determined by the presence of the communist regime, the field of social work was re-established in 1990, but the regulation of the profession occurred more than a decade later by successive social assistance laws (in 2001, 2006, and 2011) on the organisation of social work services and cash benefits, recognition of the status of social workers (law 466/2004), and a code of ethics [7]. Despite the legislative provisions, in 2012 there was a deficit of 11,000 social workers in public social work services (both at a local and county level) [8]. Other aspects that characterise the current social work system are the fact that the main focus of the professionals' work in this field is on the benefits of social work, that the procedures for allocating these benefits are bureaucratic and overly complicated, that social services are insufficient and sometimes non-existent, and that some of the needs of the communities being met by non-governmental organisations. Therefore, resources are insufficient to properly address clients' needs and there are tensions between the structural constraints and professional ethics [9]. The only national study on the profession of social work in Romania raised several key areas of concern, notably the low levels of pay and benefits, the lack of social workers in the heavily populated rural areas, and the high levels of burnout. Qualified Romanian social workers who are experiencing low wages and high stress have little incentive to remain practising in Romania and are amongst the largest nationalities of transnational social workers, often moving to western European nations such as the UK [10].

National and international literature on social work during the pandemic is emerging, though there is still much to be understood [4-6,11-25]. This paper reported on results from an ongoing mixed-methods study on social workers during the pandemic in Romania. It aimed to explore the changes posed by the new COVID-19 pandemic to the field of social work and its impact on social workers in terms of job stress and burnout.

Two conceptual models were used to frame the discussion: the theoretical framework of VUCA (Volatility, Uncertainty, Complexity and Ambiguity) to bring a new understanding of the changes and challenges perceived by social workers during the COVID-19 pandemic; and the Job Demands and Resources model (JD-R) [26] to understand job stressors and burnout and the risk and protective factors for social workers' occupational health during this highly turbulent period. The paper concludes with lessons learned by professionals at the beginning and middle phases of the pandemic (data collected July-December 2020) and suggestions for social policy and social work practitioners on how to deal with this VUCA world and the COVID-19 pandemic to prevent the risk of burnout.

\subsection{The VUCA World of COVID-19 Pandemic in Social Work}

The literature within the field of organisational psychology has explained the characteristics of the new work and business world using the VUCA conceptualisation for over 15 years. Today, the pandemic has amplified these characteristics. The acronym VUCA (Volatility, Uncertainty, Complexity, and Ambiguity) was introduced in 1987 by the United States Army War College to describe the unstable geopolitical conditions following the end of the Cold War [27]. This acronym was widely used to describe the chaotic, turbulent, and rapidly changing business environment, but can also be used in other fields, such as education, healthcare or social protection, to enable a better understanding of the world [28]. The literature review for this study could not identify applications of the framework in social work, except one study on social work education [19]. Furthermore, the four attributes of VUCA were defined and illustrated with data from the existing literature on social work during the pandemic. In the results section, this was completed with findings from the present study.

Volatility. A volatile situation can be defined as one that is unstable or unpredictable [29]. The volatility in the context of COVID-19 refers to the rapid and unexpected increase in the number of cases since the initial outbreak occurred in December 2019 [30]. Fear became part of the everyday life of people, including social workers and their beneficiaries. A 
study on fear within the social work system in Romania showed that professionals able to deal with their own fears were more efficient in helping their vulnerable clients [4]. In a volatile situation, past experience and best practices no longer provide solid indicators for identifying solutions for the present or for the future [31]. Social workers had to think outside the box and act outside the usual scope of their practice, which might lead to the crossing of professional boundaries [19] or ethical dilemmas [13].

Uncertainty refers to a situation or an event which is unclear [32], or a lack of knowledge as to whether an event will have meaningful ramifications [13]. The COVID-19 pandemic has also created a situation of uncertainty. All prediction models regarding disease transmission ultimately failed [33]. Uncertainty makes it difficult to use the past as a predictor for the future, meaning accurate predictions are extremely difficult and making decisions is a challenge. Loss of routine and uncertainty brought about increased stress on social workers. The uncertainty over health, employment, and finances impacted the social work practice [20]. Moreover, social work agencies were faced with uncertainty and the need to decide how to provide services for clients, whose needs increased [21], and new governmental restrictions and regulations were put into place. Social workers have both struggled and worked creatively to meet needs in risky and uncertain situations and to respect people's rights to privacy and involvement in important decisions about their lives [13].

Complexity refers to a situation or an event that has many interlinked and interconnected components, of which limited information is available regarding their interaction and interdependence. This was linked with ambiguity about the disease dynamics and control measures [27]. The complexity of the pandemic also lies in the fact that it affects all aspects of life-including health care, business, the economy, and social life-in complex ways.

Possibly the most overt disruption in social work practice came in the area of communication and relational work [23,34], which is considered a significant threat to the relationship-based skills on which social work has traditionally relied [17]. The shielding, social isolation, and social distancing deny the comfort offered by a face-to-face interaction, except in the greatest emergency, and also in conditions that are confusing and frightening to many clients. Frontline social workers asked to continue to do home visits, distribute food, and care for the most vulnerable are often at great risk themselves. Home visits using visors and other personal protective equipment, the prohibition of reassuring touch with fearful, distressed, or confused individuals, online conferencing, and meetings replacing more inclusive and potentially supportive multi-professional approaches challenge our preferred modes of interaction [17]. Social workers used internet connections to mitigate the level of social isolation, however lack of digital literacy skills became another problem $[5,22]$. The pandemic has caused many different forms and layers of loss, both personal and professional, and social workers are not immune to confronting them [23]. A key challenge is prioritising the service users' needs and demands, which are greater and different, while resources are stretched or unavailable [13,22]. To compensate, mutual aid seems to have been revitalised in many sites of social work practice [23]. Some areas of social work posed difficult challenges, such as hospital and hospice social work [17], residential centres for older people and those with disabilities [16], working with the homeless [24], and working with children [25]. Social workers should be vigilant to recognise disadvantaged people that experience more negative consequences due to the pandemic, such as victims of domestic violence, migrants and refugees, and other hard-to-reach populations [18,19].

Ambiguity refers to a lack of clarity regarding the meaning of an event [32]. COVID-19 began as a highly ambiguous situation: the symptoms are "ambiguous" and its containment is not straightforward [30], while many countries, including well-developed nations, were unclear about the imposition of lockdown. There was a dilemma regarding whether a complete or a partial lockdown was needed to curb the spread of the virus [27]. Romanian authorities followed WHO recommendations, thereby implementing measures in a similar manner to other countries affected by the pandemic [3]. Work patterns in the social work 
system have changed considerably during the state of emergency (March-May 2020) and state of alert (May 2020-present), ranging from remote work (from home, online, or over the phone), hybrid patterns, office work, isolation in an institution (shelters, placement centres, homes for the elderly, disabled, etc.) or suspension of work; working hours varied from normal $(8 \mathrm{~h} /$ day at the office or in the field), in terms of shifts (8-h shifts, $12-\mathrm{h}$ or 16-h shifts during the day and night) or simply regarding how long it took to accomplish a particular task $[5,14]$. The VUCA framework has the potential to provide new lenses to understand the changes and challenges of the COVID-19 pandemic in social work and transfer the experience of work and organisational psychology into strategies and actions for managers/leaders and professionals in the pursuit of a better adaptation to life in the 'new normal' state of emergency [15] and the unknown future.

\subsection{Job Stress and Burnout among Social Workers}

Despite the key words 'occupational stress,' 'work stress,' and 'job stress' being used in many scientific articles, in the course of time up to now, the scientific community has not reached an agreed definition. There has been considerable debate about whether job stress should be defined in terms of the person, the environment, or both [35]. Some authors argue that stress is the result of the disturbances of the equilibrium between the demands that employees are exposed to and the resources they have access to [36]. Adverse work experiences (i.e., adverse characteristics, events, or situations in the work environment) contribute to the personal (e.g., poor quality of work life, low job satisfaction, burnout, and lack of motivation) and organisational (e.g., increased sickness absence, stress related workers' compensation claims, poor productivity, and high turnover) outcomes normally attributed to job stress. Therefore, job stress occurs when work characteristics contribute to poor psychological or physical health and stressors refer to the work-related characteristics, events, or situations that give rise to stress [35]. Many authors have studied the issue of stress in social workers, trying to identify the main stressors that cause and maintain the state of stress among them. In summary, factors identified as contributing to the social workers' stress included the nature of social work practice, especially the tension between philosophy and work demands, the organisation of the work environment [37], and the obstacles related to regulations and legislation [9]. Even though stress seems to be embedded in the social work profession, chronic workplace stress causes high pressure on the person's resources to deal with it in an adaptive and healthy manner. In the field of occupational health psychology, the burnout syndrome is defined to capture the cumulative nature of stress and negative impact on well-being.

Firstly, as introduced by Herbert Freudenberger in 1974 [38], the term burnout was defined as a phenomenon observed among human service workers who had to deal with emotionally demanding individuals and ended up emotionally and physically drained. Since then, the majority of burnout studies have been based on Christina Maslach's [39] conceptualization of burnout as comprising three components: emotional exhaustion (feelings of being overextended and depleted of emotional and physical resources), depersonalisation or cynicism (negative or excessively detached responses to various aspects of the job), and diminished personal accomplishment (feelings of incompetence and a lack of achievement at work). Currently considered an occupational disease, the burnout syndrome affects $13-27 \%$ of the active population in multiple occupational sectors of the modern world [40]. It was introduced in the 10th Revision of the International Classification of Diseases (ICD-10) and was recently revised by the World Health Organisation within ICD-11 as an occupational phenomenon and not as a medical condition: "a syndrome conceptualized as resulting from chronic workplace stress that has not been successfully managed. It is characterised by three dimensions: (a) feelings of energy depletion or exhaustion; (b) increased mental distance from one's job, or feelings of negativism or cynicism related to one's job; (c) reduced professional efficacy. Burnout refers specifically to phenomena in the occupational context and should not be applied to describe experiences in other areas of life" [41]. There are authors [42] who criticise the Maslach three-dimensional definition 
of burnout and conceptualise burnout as a more unidimensional construct of fatigue and exhaustion. This is in accordance with the historical development of the burnout concept and also with a recent definition: burnout is "a state of physical, emotional and mental exhaustion that results from long-term involvement in work situations that are emotionally demanding" [42].

Previous research has shown that social workers are a profession at high risk for developing burnout syndrome [37,43-49]. For the employees who work in this field, studies have repeatedly shown that those experiencing burnout have undergone long periods of work-related stress and job demands [50]. Comprehensive reviews of the burnout literature have consistently suggested that among the stressors that have been associated with the social workers' burnout are the high number of caseloads, limited supervisory support, working with clients with complex social situations [48], the years spent working, lacking social support from managers and colleagues [47], lower self-efficacy [51], and higher levels of role-related stress such as high role conflict, role ambiguity, and role overload [43,52]. A qualitative study of Romanian social worker burnout identified the following main risk factors: heavy case-loads, time constraints, the categories of clients with whom they work, limitations of social work interventions, lack of appreciation and reward for their work, lack of support from supervisors and colleagues, and lack of involvement in family life [44].

Burnout impairs the social workers' ability to function professionally and, consequently, their ability to provide quality services to the clients that they serve [53]. The clinical picture of the burnout syndrome comprises a complex interplay of physical and psychological symptoms, an association of symptoms of social dysfunction, psychosomatic and somatic disorders, and emotional and psychological distress [40]. When compared with 26 other occupations, social service work was one of the six professions with the worst experiences in terms of physical health, psychological well-being, and job satisfaction in the workplace [54], while the incidence of mental disorders (e.g., depression, anxiety) [55] associated with burnout was considerably higher for social workers than for other professions [37].

Several theoretical approaches have been used to describe, explain, and predict burnout [46]. Given the objectives of this study, we considered that the most appropriate theoretical framework was the Job Demands-Resources model (JD-R) [26]. This is currently the most popular framework in occupational health psychology to investigate the relationships between job characteristics and employee well-being [56]. Also, the JD-R model is applicable to various occupational settings in order to detect the consequences of specific work environments on employee well-being and employee performance.

\section{Job Demands-Resources Theory}

The JD-R model is an organisational theory that grew out of job stress research [57]. It was introduced in the English literature 15 years ago [58]. Since then, the JD-R model and the job demands-resources distinction has been applied in thousands of organisations, inspired hundreds of empirical studies, and has been used by many Occupational Health and Safety/Workplace Health and Safety regulators and government agencies around the world (especially in the United Kingdom, Europe, Canada, and Australia) [26]. The model was tested, and with the JD-R theory we can understand, explain, and make predictions about employee wellbeing, such as burnout, health, motivation, work engagement, and job performance [59]. According to this model, all working environments or job characteristics can be classified using two different categories, namely job demands and job resources.

Job demands are defined as those physical, psychological, social, or organisational aspects of the job that require sustained physical and/or psychological effort (e.g., role ambiguity, role conflict, role stress, stressful events, workload, emotional labour, and work pressure) and are therefore associated with certain physiological and/or psychological costs $[26,60]$. In the social work literature, according to the JD-R theory, there are two great categories of job demands: "internal and external demands". Internal demands are those categorised as pressures which are most likely to be experienced within the context of 
the social care team or office environment. In contrast, "external demands" are those that originate from outside of the office environment, yet have a detrimental impact on the social worker's role [61]. Job resources refer to those physical, psychological, social, or organisational aspects of the job that are functional in achieving work goals, reduce job demands and the associated physiological and psychological costs, or stimulate personal growth, learning, and development (e.g., social support, performance feedback, autonomy, opportunities for development, degree of participation in decision making) $[26,60]$. In the case of social workers, the most relevant job resources which can buffer against the negative effects of demands are: the rewarding nature of the role, peer support and management support [61], human resource orientation, and openness as dimensions of the psychological climate [62].

The JD-R theory integrates two basic psychological processes: a stress process and a motivational process. Hence, job demands and resources instigate two very different processes, namely a health-impairment process (starting with job demands) and a motivational process (starting with job resources), which are largely independent $[26,63]$. In this article we focused mainly on one of the two processes, namely stress and burnout. Essentially, when job demands are chronically high and are not compensated by job resources, employee' energy is progressively drained and this may result in a state of mental exhaustion, or 'burnout'. This may lead to negative outcomes for the individual (poor health) as well as for the organisation (poor performance) [63]. The core of burnout is fatigue and exhaustion [42], which we investigated in this study. Furthermore, the underlying job demands perceived as stressors and job resources of this unprecedented period of time were explored.

\section{Materials and Methods}

\subsection{Aims, Hypothesis and Research Questions}

In the midst of the COVID-19 pandemic, which has affected almost every aspect of our work and lives, this mixed-methods study aimed to explore how social work professionals in Romania are experiencing an increasingly 'VUCA' (volatile, uncertain, complex and ambiguous) organisational context, leading to high job demands and presumably stress and burnout. The aim of the quantitative part of the study was to assess the levels of job stress and burnout of social workers during the pandemic and understand their relationship with job demands and resources.

Hypothesis 1. The high level of perceived job stress is associated with a high level of burnout.

Hypothesis 2. The social workers that perceived a high workload without organisational support have a higher score of work-related burnout than those that perceived a high workload with organisational support.

The aim of the qualitative part was an in-depth understanding of the changes of the COVID-19 pandemic to the field of social work and how professionals are experiencing them. The following research questions were formulated:

Research Question 1: How is the VUCA world created by the COVID-19 pandemic experienced by social workers?

Research Question 2: What are the job demands perceived as stressors and job resources of social workers during the COVID-19 pandemic?

Research Question 3: What can be learnt about how to deal with the VUCA world of the COVID19 pandemic for the social work profession, system, and professionals in order to contribute to the development of burnout prevention programmes? 


\subsection{Data Collection Method}

In this study, we collected both qualitative and quantitative data from social workers from Romania. Data were mainly collected online through the free application Google Forms in July to December 2020, though some questionnaires were also distributed in printed format. The population for the study was selected in a non-probabilistic way and consisted of 83 social workers from one county of Romania. The survey took approximately $45 \mathrm{~min}$ to complete. The research received the approval of the Ethics Commission in social research from Transilvania University of Brasov, Romania.

We used the convergent mixed-method design, specifically the questionnaire variant [64]. The convergent design involves quantitative and qualitative data collection simultaneously, and both strands had equal emphasis. The questionnaire variant is used when the researcher includes both open- and closed-ended questions on a questionnaire [65]. The reasons for choosing this option were pragmatic in nature. Due to the social workers' overloading during this period, the rate of non-responses was high. Through this variant, in which we combined open and closed questions, we were able to obtain a clearer understanding of the different aspects faced by social workers during this period, investigating the same sample of subjects only once.

Taking into consideration the potential problem of common factor bias, we implemented some preventive procedures. We pretested the instrument and, based on the social workers recomandations, we reduced the length of the instrument, and we refined the instrument to make the wording of the questions clearer, more concise, and accurate to reduce cognitive effort. Additionally, we tried to motivate the respondents to provide accurate answers by promising feedback to respondents. For quantitative data, we applied the post-hoc Harman's single-factor test, which is $31.2 \%$. The total variance extracted by one factor was less than the recommended thereshold of 50\% meaning, that our data seemed to not have a problem with common method bias [66].

The analyses of the two types of data were done separately and independently of each other using specific analysis procedures. In the end, the two types of results were integrated. According to mixed methods literature, there are several ways to integrate the results [64,67]. In this study, we chose to first present the quantitative results, followed by the qualitative findings, and integrated the data in the discussion section of the article, illustrating quantitative results with qualitative findings and discussing them in light of the literature [64]. Moreover, the qualitative data allowed us to obtain, from the professionals in the field of social work, a list of possible solutions aimed at improving the organisation and development of the current social work system.

\subsection{The Research Instrument}

The survey included questions for collecting both qualitative and quantitative data. For quantitative data, the Copenhagen Burnout Inventory was used [42,48], and the version was translated and adapted into Romanian (CBI-R) on a national sample of medical staff/nurses [40]. The results obtained supported the high level of reliability, construct, and predictive validity of the variant translated into the Romanian language. The CBI-R consists of three scales which differentiate between personal burnout (PB), work-related burnout (WB), and client-related burnout (CB). It is more suitable to the pandemic situation, which posed significant stress on both personal life and work, and also the nature of the relationship with clients, which has changed dramatically. Comparing the personal exhaustion scale with the work-related exhaustion scale, people who are tired because of work stress are differentiated from those who attribute the fatigue to non-working core factors, such as health or family issues. The three dimensions were demonstrated to have high Cronbach's Alpha scores (Table 2). Additionally, a closed question which measures the general level of perceived job stress during the pandemic situation (SD) was used (On a scale of 1 to 10, what is the level of ocupational stress you perceive now?). We also measured the intentions for professional changes (PC) (During this period, have you considered resigning from work? During this period, have you considered changing 
the category of beneficiares? During this period, have you considered changing your profession?) and the first five biggest challenges in social work, the biggest concerns during this period, and the job resources offerd by the organisation to cope profesionally with this difficult period.

For the qualitative data, several open questions were addressed regarding what a social worker's activity meant during the pandemic, what changes the pandemic brought in the content and context of the work, what the challenges were and how they managed them, what the lessons they learned from this period were, and the lessons the system could learn to better cope in other similar contexts. The last part of the instrument contained a series of socio-demographic variables such as gender, age, marital status, whether or not participants had children under 18 years old, the system where they worked (public/private), the field in which they worked, years of experience in the field, training type, level of competence and professional position, their medical situation related to COVID-19, and the place of work.

\subsection{Participants}

The 83 social workers who participated in this study were from one county of Romania, from the Transilvania region. They belonged to different fields of intervention in social work, such as addictions, adolescents, the elderly, child/family protection, community development, criminal justice, adults with disabilities, homeless people, providing social work benefits, health, mental health, social work in school, social economy, minorities, trafficked persons, migrants, and drug and alcohol users. In terms of gender, the participants were mostly female (77); the low number of male participants reflects the reality in the Romanian social work system, the occupation being chosen mainly by women. A national study [7] indicated the proportion of social workers was $88 \%$ female. There were 21 persons aged between 20-30 years old, 45 between 31-45 years old, and 16 over 45 years old. Out of the total sample, 59 worked in the public system, 23 in the private system, and 67 had a degree in social work. Other information about the participants is summarised in Table 1.

Table 1. Sociodemographic characteristic of respondents $(\mathrm{N}=83)$.

\begin{tabular}{|c|c|c|c|}
\hline & Category & Count & Percent \\
\hline \multirow{2}{*}{ Gender } & Female & 77 & $92.8 \%$ \\
\hline & Male & 6 & $7.2 \%$ \\
\hline \multirow{3}{*}{ System type } & Public & 59 & $72 \%$ \\
\hline & Private & 23 & $28 \%$ \\
\hline & n.r. & 1 & \\
\hline \multirow{4}{*}{ Age } & 20-30 years old & 21 & $25.3 \%$ \\
\hline & $31-45$ years old & 45 & $54.2 \%$ \\
\hline & over 45 years old & 16 & $19.3 \%$ \\
\hline & n.r & 1 & 1.2 \\
\hline \multirow{2}{*}{ Children under 18 years old } & They have & 41 & $49.4 \%$ \\
\hline & They do not have & 42 & $50.6 \%$ \\
\hline \multirow{4}{*}{ Current Relationship Status } & Never married & 13 & $15.7 \%$ \\
\hline & Married & 52 & $62.7 \%$ \\
\hline & Partnered & 12 & $14.5 \%$ \\
\hline & Divorced & 6 & $7.2 \%$ \\
\hline \multirow{3}{*}{ Experience as social worker } & Under 10 years & 47 & $56.6 \%$ \\
\hline & Over 10 years & 35 & $42.2 \%$ \\
\hline & n.r & 1 & $1.2 \%$ \\
\hline
\end{tabular}


Table 1. Cont.

\begin{tabular}{|c|c|c|c|}
\hline & Category & Count & Percent \\
\hline \multirow{5}{*}{ Highest Academic Degree } & Bachelor's & 31 & $37.3 \%$ \\
\hline & Master's & 38 & $45.8 \%$ \\
\hline & Doctorate & 3 & $3.6 \%$ \\
\hline & Professional Degree & 8 & $9.6 \%$ \\
\hline & No specialised training & 3 & $3.6 \%$ \\
\hline \multirow{6}{*}{ Stage of competence } & Without a certificate of free & 18 & $21.7 \%$ \\
\hline & practice & 7 & $8.4 \%$ \\
\hline & Debutant & 16 & $9.3 \%$ \\
\hline & Practitioner & 7 & $8.4 \%$ \\
\hline & Specialist & 34 & $41 \%$ \\
\hline & $\begin{array}{l}\text { Principal } \\
\text { Nr. }\end{array}$ & 1 & $1.2 \%$ \\
\hline \multirow{3}{*}{ Professional position } & With leadership position & 10 & $12 \%$ \\
\hline & No leadership position & 71 & $85.5 \%$ \\
\hline & n.r. & 2 & $2.4 \%$ \\
\hline \multirow{2}{*}{ Degree in social work } & Yes & 67 & $80.7 \%$ \\
\hline & No & 16 & $19.3 \%$ \\
\hline \multirow{17}{*}{ Domain $^{1}$} & Addictions & 6 & $7.3 \%$ \\
\hline & Adolescents & 21 & $26.8 \%$ \\
\hline & the elderly & 35 & $42.7 \%$ \\
\hline & child/family protection & 41 & $51.2 \%$ \\
\hline & community development & 14 & $17.1 \%$ \\
\hline & criminal justice & 7 & $8.5 \%$ \\
\hline & adults with disabilities & 30 & $37.8 \%$ \\
\hline & homeless/displaced people & 9 & $11 \%$ \\
\hline & $\begin{array}{c}\text { providing social assistance } \\
\text { benefits }\end{array}$ & 15 & $19.5 \%$ \\
\hline & Health & 7 & $9.8 \%$ \\
\hline & mental health & 5 & $6.1 \%$ \\
\hline & social assistance in school & 3 & $3.7 \%$ \\
\hline & social economy & 2 & $2.4 \%$ \\
\hline & Minorities & 19 & $24.4 \%$ \\
\hline & trafficked persons & 6 & $7.3 \%$ \\
\hline & Migrants & 2 & $2.4 \%$ \\
\hline & drug and alcohol users. & 10 & $12.2 \%$ \\
\hline
\end{tabular}

${ }^{1}$ Uncalculable data. A social worker may conduct his/her activity in several fields of activity.

\subsection{Data Analysis}

The quantitative data were analysed using IBM SPSS Statistics (version 23). Each subscale of CBI-R (personal burnout (PB), work-related burnout (WB), and client-related burnout (CB)) was scored between 100 to 0 , where 100 indicated a high level of burnout and 0 a lack of burnout [42]. Descriptive statistics (mean, standard deviation, Cronbach's alpha) are presented in Table 2. Based on this information, we established four categories of burnout (Table 3). Higher scores on the CBI-R were indicative of more burnout, whereas lower scores indicated less burnout [42]. For testing hypotheses, Spearman's correlation coefficient and Chi square were used.

The procedure followed in the processing of qualitative data was content analysis. This method allowed us to focus on the characteristics of language as communication by paying attention to the content or contextual meaning of the text. Qualitative content analysis goes beyond merely counting words to examine language intensely for the purpose of classifying large amounts of text into an efficient number of categories that represent similar meanings [68]. By this method, we aimed "to provide knowledge and understanding" about what transformations social work underwent during the pandemic, from the perspective of the professionals who practise in this field [69]. We used a directed approach 
to content analysis, as we started from a pre-existing theoretical framework. Therefore, in coding the material collected through open-ended questions (e.g., "Can you tell us in a few words what your work as a social worker meant during the pandmic?"), we resorted to the theoretical VUCA framework to highlight how the adjectives of volatility, uncertainty, complexity, and ambiguity were reflected within the work of social workers [70].

\section{Results}

Our approach to data analysis and interpretation was: firstly, to respond to the research hypothesis and questions in the order in which they are asked, reporting separately on the quantitative and qualitative findings; secondly, the discussion section integrates data from both strands commented on in relation to existing scientific literature.

\subsection{The Social Workers' Level of Perceived Job Stress and Burnout during the Pandemic}

When asked about how they perceived the level of job stress on a scale from 1 to 10 , social workers mentioned a high level during this period of pandemic (SD) $(M=8.61$, $\mathrm{SD}=1.62)$. Moreover, people in the state system mentioned a higher level of perceived stress during the pandemic $(\mathrm{M}=8.97, \mathrm{SD}=1.48 ; \mathrm{M}=7.70 . \mathrm{SD}=1.66 ; \mathrm{t}(80)=3.36, p=0.001)$ (Table S2, Supplementary Materials). Except for this variable, there were no significant correlations between stress and burnout and socio-demographic variables.

The analysis of the impact of this environment characterised by VUCA from the perspective of burnout syndrome indicated that the average scores for each of the three types of burnout were as follows: personal burnout at 55.9 was the highest, work-related burnout was nearly the same at 52.5, and client-related burnout was lower at 38.4 (Table 2). Higher scores on the CBI-R were indicative of more burnout, whereas lower scores indicated less burnout. These findings illustrated a medium level of personal and work-related burnout, while personal burnout and work-related burnout scores were not significantly different from each other (Table S3, Supplementary Materials).

Table 2. Descriptive statistics- burnout scales.

\begin{tabular}{ccccccc}
\hline & N & Minimum & Maximum & Mean & SD & $\begin{array}{c}\text { Cronbach's } \\
\text { Alpha }\end{array}$ \\
\hline $\begin{array}{c}\text { Personal } \\
\text { burnout (PB) }\end{array}$ & 83 & 0 & 100 & 55.9 & 19.2 & 0.87 \\
\hline $\begin{array}{c}\text { Work-related } \\
\text { burnout (WB) }\end{array}$ & 83 & 0 & 100 & 52.5 & 20.6 & 0.82 \\
\hline $\begin{array}{c}\text { Client-related } \\
\text { burnout (CB) }\end{array}$ & 83 & 0 & 100 & 38.4 & 23.2 & 0.88 \\
\hline
\end{tabular}

Starting from the scores obtained (Table 2), we established four categories of workrelated burnout level (Table 3). Findings suggested that nearly $44.2 \%$ of all participants scored in a range that indicated a medium to high level of work-related burnout, and 15.7\% a high to very high level. About one quarter of the sample $(27.7 \%)$ reported low to medium levels of work-related burnout, while $14.5 \%$ reported none to low burnout symptoms. The results showed a large upper-middle group (medium to high level of burnout), which is at risk of progressing to higher levels of burnout over time. Descriptive data about the items of scale are presented in Table S1 (Supplementary Materials). 
Table 3. Descriptive statistics: level of work-related burnout.

\begin{tabular}{cccc}
\hline & $\mathbf{N}$ & Percent & Interval Values \\
\hline None to low level of burnout & 12 & $14.5 \%$ & {$[0 ; 25]$} \\
\hline Low to medium level of burnout & 23 & $27.7 \%$ & {$[25 ; 50]$} \\
\hline Medium to high level of burnout & 35 & $44.2 \%$ & {$[50 ; 75]$} \\
\hline High to very high level of burnout & 13 & $15.7 \%$ & {$[75 ; 100]$} \\
\hline
\end{tabular}

Hypothesis 1. The high level of perceived job stress is associated with a high level of burnout.

Social workers who experienced a higher level of job stress during the pandemic (SD) also scored higher on personal burnout $(\mathrm{PB})\left(\mathrm{r}_{\mathrm{S}}=0.452, p=0.000\right)$ and work-related burnout (WB) $\left(r_{s}=0.37, p=0.003\right)$. The hypothesis was confirmed related to the personal and workrelated burnout but was not confirmed related to the client-related burnout. Comparing the personal exhaustion scale with the work-related exhaustion scale, it was observed that people who were tired because of personal circumstances and highly challenged during the pandemic were also exhausted because of work-related factors. We could not differentiate from the data how the two areas of stress and physical and emotional exhaustion related to each other. The correlations between the level of self-perceived job stress and the CBI-R scale suggests that chronic stress is not caused by elements related to the particularities of working with beneficiaries, but is caused by other stressors.

The analysis of the answers regarding the choice of "the first five biggest challenges in social work during the pandemic" indicated the following hierarchy: increased workload $(52.8 \%)$, lack of direct contact with some of the clients (44.4\%), lack of material/financial resources to support more beneficiaries $(43.1 \%)$, the desire to help more than one was able to $(43.1 \%)$, new rules and national decisions that affected one's work $(37 \%)$, lack of support from the management of the institution (34.7\%), and incoherence of decisions or information transmitted from official sources that directly affected the work of the social worker $(22.2 \%)$. The biggest concerns, in order, were: the risk of being a carrier (asymptomatic) and implicitly the risk of infecting others (beneficiaries or relatives) (30.1\%), the risk of contamination $(23.2 \%)$, the lack of a professional support network (institutions that have suspended their activity) (15.1\%), risk of job loss (technical unemployment) (11\%), changes in the workplace (e.g., digitisation, learning new skills in a very short time) (9.6\%), lack of professional support from colleagues in telework or technical unemployment $(6.8 \%)$, and others $(4.1 \%)$.

In this context, the high level of burnout correlated significantly with the intention to make professional changes (the intention to resign from work ID $=24.1 \%$, the intention to change their profession IP $=3.7 \%$ ). However, the level of burnout did not correlate with the intention to change the category of beneficiaries because, as we mentioned above, it is not the particularities of working with the beneficiaries that generate stress but organisational factors (Table S4, Supplementary Materials).

Hypothesis 2. The social workers that perceived a high workload without organisational support have a higher score of work-related burnout than those that perceived a high workload with organisational support.

To test this hypothesis, we compared the average scores for work-related burnout (Table S5, Supplementary Materials) in two categories: those who perceived they had a higher volume of work and received organisational support $(\mathrm{M}=49.51, \mathrm{SD}=23.28)$; and those who perceived they had a higher volume of work and did not receive organisational support $(\mathrm{M}=67.18, \mathrm{SD}=18.18)$ The hypothesis was confirmed: where social workers perceived a higher volume of work during this period, the organisational support provided made a difference to burnout scores. Thus, those who perceived that they received organisational support had a lower level of work-related burnout than those who did not 
perceive that they received organisational support. Therefore, the high demand at the organisational level manifested by more working hours and the lack of organisational support makes a difference in the level of burnout. We cannot deduce from this data what the types of job demands that generated a busy schedule were and what the job resources they expected from the organisation were. Qualitative data could provide more clarity.

\subsection{The VUCA Characteristics Reflected in the Social Work Environment}

Research Question 1: How is the VUCA world created by the COVID-19 pandemic experienced by social workers?

In the VUCA world created by the COVID-19 pandemic, social workers' activity was characterized by a series of significant changes, one of them referring to the working manner of professionals in this field. Thus, $23.8 \%$ experienced work in a hybrid system and there were also situations in which they were sent into technical unemployment (3.6\%). In order to avoid dismissal or unemployment, some of the social workers were relocated to other fields of activity $(6 \%)$, and some of them had to work more than usual. However, the majority of social workers had to work under normal conditions $(62.7 \%)$, having to cope with virus exposure and fears related to getting sick. Although most of them did not experience problems due to COVID-19 (63.9\%), there was a significant percentage who were in the situation of home isolation $(34.9 \%)$ or hospitalisation $(1.2 \%)$.

From the qualitative data analysed, it appears that social workers' activity during the pandemic was characterised by volatility, as it involved major and rapid changes in a relatively short period of time. The most significant changes experienced by social workers were represented by the large workload and the restrictions imposed on working with clients (masks, social distancing, and online meetings). The social workers had to adapt to the changes imposed by various legislative changes, draw up urgent statistical situations, and carry out activities other than those provided in the job description (Table 4). Unemployment and job change to another organisation or service, or to another team, were other major changes that some of the social workers faced during this period. The presence of volatility was also supported by emotional changes experienced by professionals in this field, and many of them remembered feeling: pressure from their organisation, stress, insecurity, chaos, panic, fear and frustration, and new emotions or emotions experienced at a much higher intensity compared with the pre-pandemic period.

The social workers investigated also stated that, throughout this period, they felt the need for better communication with their leaders (those with leadership/decision-making roles), which reflects insufficient information and a lack of clarity regarding what to do or what is going to happen. In the VUCA perspective, this feature is called uncertainty. Unfortunately, uncertainty makes it almost impossible to use the past as a predictor for the future, meaning making predictions is extremely difficult and decision-making is a challenge (Table 4). The data collected showed that the lack of predictability that characterises the situation created by the pandemic was felt by social workers investigated in terms of decisions made or even by the lack of action of some of the managers of their organisations. In order to support the presence of uncertainty in the social workers' professional life during the pandemic, the answers to the question "what are the adjectives that best describe your work environment during this period" are considered; "uncertain, unstable, unpredictable, insecure, chaotic, confused, and disorganised" were the adjectives used by 29 respondents to describe the uncertainty and lack of predictability generated by the pandemic.

The third characteristic of the VUCA world created by the pandemic is complexity. The work of social workers during this period is different and much more complex than it was before the pandemic and it is influenced by many factors (Table 4) such as:

1. Restrictions imposed by an organisation and the legislation (mask, equipment, and social distance);

2. Beneficiaries (do not know how to use the technology or do not have it); 
3. Managers (lack of support for their employees, incoherence of decisions);

4. The environment/way of carrying out the activity (from home, online, at the door, and etc.);

5. Collaboration with other institutions/organisations.

Therefore, social workers, besides having to comply with the restrictions imposed by an organisation and the legislation on the use of protective and sanitation equipment, also had to adapt to a new work environment, whether they worked from home, online or, on the contrary, exclusively on site. The transition from offline to online was, in some situations, disturbing both for social workers and for their clients, who either did not have the necessary equipment (computer, smartphone) or did not know how to use it. Another factor that contributed at the level of complexity was, in some cases, the lack of support or inconsistency of the decisions made by the organisation's management. Lastly, the social worker also had to deal with changes in inter-institutional collaborations: some organisations suspended their activity during the emergency, and others worked exclusively online. In a VUCA framework, the ambiguity of the environment is the result of all the above features. It is rendered by the inability to provide "yes/no" solutions and, hence, by multifariously valid alternatives [31]. Many social workers talked about the ambiguity of tasks and activities. The most obvious lack of clarity was found in the case of working procedures and methodological norms, indicating them as an important obstacle in the way of carrying out professional activity. Additionally, the ambiguity in the work environment put some of the social workers in difficult situations, especially in the absence of organisational support, being forced to overcome obstacles "on their own": "We did not receive support. We adapted to the situation and took things as they came, trying as much as possible to find the best solutions to cope with the period" (Table 4). A conclusion to the changes that took place in the social workers' work environment and the way in which they were experienced by professionals is contained in the words of one of them: "Everything I would call stress before the pandemic, now I have discovered it threefold".

Table 4. VUCA in the social workers' activity.

$\begin{aligned} & \text { VUCA } \\ & \text { Framework }\end{aligned}$
What Is it?
A volatile situation is one characterised
by instability and unpredictability.
Volatility is the closest general definition
of: "relatively unstable change".

"During the state of emergency, the social service within the foundation where I work was suspended. Then I went into technical unemployment, which triggered a state of disquiet, both for me and for the beneficiaries we work with. After two and a half months of unemployment, I returned to reduced $4 / 5$ working hours, and the activity was very intense."

"My activity as a social worker has undergone many changes during this period: the category of beneficiaries (I had not worked with children, only with the elderly), social service (as the service for children suspended its activity), and social needs (the elderly needed more security, and as a social worker I offered telecare kits)"

"... There have been many changes in the way social services are provided."

"Chaos in the institution: I received tasks that would change in $5 \mathrm{~min}$, only to change again after another $10 \mathrm{~min} .{ }^{\prime \prime}$ 
Table 4. Cont

\begin{tabular}{|c|c|c|}
\hline $\begin{array}{c}\text { VUCA } \\
\text { Framework }\end{array}$ & What Is it? & Quotes from Social Workers \\
\hline \multirow{5}{*}{ Uncertainty } & \multirow{5}{*}{$\begin{array}{l}\text { Uncertainty is a term used to describe a } \\
\text { situation characterised by a lack of } \\
\text { information/ knowledge. } \\
\text { Uncertainty makes it difficult to use the } \\
\text { past as a predictor for the future, making } \\
\text { predictions is extremely difficult, and } \\
\text { making decisions is a challenge. }\end{array}$} & $\begin{array}{l}\text { "I discovered that amid the panic created, people with } \\
\text { decision-making power made erroneous or absurd decisions, and } \\
\text { others withdrew "at home" and did not take any action in terms of } \\
\text { community interventions." }\end{array}$ \\
\hline & & $\begin{array}{c}\text { "... at the beginning of the pandemic, better top-down } \\
\text { communication and maybe more time to make certain decisions } \\
\text { would have been needed." }\end{array}$ \\
\hline & & $\begin{array}{l}\text { "The college of social workers doesn't even put us in touch with each } \\
\text { other, not to mention solutions or representation, I have no one to } \\
\text { turn to in order to ask questions, to ask for clear methodological } \\
\text { norms or an opinion; the leadership does not know much, but it } \\
\text { claims that we know the laws very well." }\end{array}$ \\
\hline & & "During this period, we faced the inconsistency of decisions ..." \\
\hline & & "Fear, chaos, uncertainty, change, and rigidity." \\
\hline \multirow{4}{*}{ Complexity } & \multirow{4}{*}{$\begin{array}{l}\text { A complex situation is characterised by } \\
\text { the existence of several interconnected } \\
\text { parts/elements/factors. }\end{array}$} & $\begin{array}{l}\text { "I dare say this period made it very difficult to carry out our } \\
\text { activities, we encountered multiple obstacles and blockages, } \\
\text { everything is much more difficult than before, I cannot consider that } \\
\text { there are aspects to determine me, to make me work easier during } \\
\text { this period, on the contrary." }\end{array}$ \\
\hline & & $\begin{array}{l}\text { "At the moment, social distance makes it difficult for us to work with } \\
\text { children, we keep 1-m distance, we wear a mask, we don't touch each } \\
\text { other, we can't hug them, and the children miss this closeness." }\end{array}$ \\
\hline & & $\begin{array}{l}\text { "Technology where those we work with did not have } \\
\text { basic knowledge." }\end{array}$ \\
\hline & & $\begin{array}{l}\text { "The fight against bureaucracy, the need to identify immediate } \\
\text { solutions for a person at risk". "Homeless person with lower limb } \\
\text { amputation without a permanent home in the city, rejected by all } \\
\text { social institutions in the county; the solution was the acceptance in } \\
\text { another county located } 500 \text { km distant, after all possible centres in the } \\
\text { county were contacted." }\end{array}$ \\
\hline \multirow{4}{*}{ Ambiguity } & \multirow{4}{*}{$\begin{array}{l}\text { Ambiguity has been defined as a lack of } \\
\text { clarity that surrounds an event and its } \\
\text { meaning, or the causes behind the things } \\
\text { happening which are unclear and } \\
\text { difficult to understand. }\end{array}$} & $\begin{array}{c}\text { "The lack of a procedure to guide us in our daily work, the fear of } \\
\text { interacting with potential beneficiaries at first, when there was no } \\
\text { protective equipment, and the lack of relevant information about this } \\
\text { virus." }\end{array}$ \\
\hline & & "... and ambiguous overnight laws to be applied urgently." \\
\hline & & $\begin{array}{l}\text { "inconsistency of decisions or information transmitted from official } \\
\text { sources that directly affect the social worker 'activity." }\end{array}$ \\
\hline & & $\begin{array}{c}" . . . \text { a system of giving hot meal vouchers by electronic vouchers to } \\
\text { vulnerable people has been devised without clearly specifying how } \\
\text { they can get in their possession, what categories should be included, } \\
\text { which leaves much room for interpretation; }\end{array}$ \\
\hline
\end{tabular}

Research Question 2: What are the job demands perceived as stressors and job resources of social workers during the COVID-19 pandemic?

From the analysis of the answers to the open questions, it resulted that the current work environment was described as "stressful" (24 out of 83),"tense, loaded, difficult, and agitated" (20 out of 83), and "tiring, exhausting, and overwhelming" (16 out of 83). The words of one of the social workers was eloquent to emphasise the burden and pressure felt during the same period: "hours of work, stress and exhaustion, life in danger." There are 
social workers who used other adjectives, such as hostile, ugly, rigid, limiting/restrictive, frustrating, vulnerable, or cold and distant.

The job demands perceived as job stressors mentioned by social workers refer to: workload ("the increase in the number of cases and social situations", "worked extra hours to deal with tasks, of which not all were logical"), changes related to the workplace or content ("quarantine in the workplace and distance from the family", "frequent changes in the object of work have generated stress"), management ("external pressure of direct supervisors") the pace of change, chaos, and uncertainty ("because of emergency ordinances, chaos and panic installed"), role ambiguity and conflicting demands ("clearer work procedures", "urgent data is required ... not used ... criteria are changed and everything must be redone"), bureaucracy ("the fight against bureaucracy), changes related to the use of skills/digitalisation ("I found it difficult to interact with disabled persons, especially with children by means of web camera"), physical protection measures/demands ("shortness of breath and headaches due to wearing a mask", "exhaustion due to difficulty working in protective suits"), emotional demands ("mitigating the fears of beneficiaries", "the fury of citizens towards the state institutions", "notification of some situations of non-observance of human right"), and staffing problems.

The aspect of fear and risk to one's own health and that of the family was mentioned to a smaller extent (13 out of 83 ) when participants were asked about the description of the current work environment through several adjectives, but it was included in many reports of various work experiences: "high exposure to SARS COV2", "I think the hardest part was working with the public during the emergency"; "The detailed evaluation report involves first of all field visits ... the risk of moving from one community to another, of making contact with the beneficiaries who were, in their turn, reluctant towards us". When asked about what job resources were helpful to cope professionally with this 'difficult' period, social workers mentioned firstly the support from colleagues/co-workers (54 out of 83 ), secondly support from the manager (15 out of 83), and thirdly the beneficiaries or the type of work ( 9 out of 83 ). A few also mentioned their work partners/collaborator (5). The question "How has the organisation supported/helped you?" led to a limited number of categories that were most related to the protection equipment and sanitary products, updated information and guiding, support, and understanding, and even with job retention. When asked about job resources, a large number of respondents focused mostly on limited or lacking resources, such as: lack of support from the management team and trust in leadership ("the management often does not have time, does not take clear measures", "incoherent decisions", "a better top-down communication"), insufficient supervisory support and lack of availability of tools (protective equipment, telephones with Internet connection), lack of recognition of the status of the social worker profession in terms of its true value and social contribution ("social care is just as important as health care"), lack of recognition of work performance ("their merits are not recognised and the impossible is expected of them"), and the lack of an adequate reward ("I understood how much we had to sacrifice without being rewarded, but I knew that!"). Some social workers intuitively related high job demands and lack of job resources to explain the level of stress experienced: "the workload is enormous and neither the management nor other departments understand the pressure put on the social workers' shoulders"; "we have neither decision-making power, nor support, but we have only requests, responsibilities and complaints".

Among the psychological and physical symptoms of stress and burnout experienced by social workers are emotional pressure and exhaustion, the feeling of being overwhelmed, a high level of fatigue, the fear of interacting with beneficiaries while simultaneously managing their fears and panic, and fatigue accumulated in trying to capture online attention. Despite the challenging work context, some of them managed to cope with the new situation in a healthy way (lack of burnout) and perceived the current work environment as motivating, interesting, activating, and professionally captivating (20 out of 83 ). One social worker vividly expressed this process: "at the very beginning of the 
pandemic it was stressful and tiring. Currently we have adapted to the new restrictions and I would characterise it as follows-safe and engaging". Considering the size of the challenge due to the change and complexity of the new environment, these changes generated "an inner conflict between what we need to do and what we can do in such situations", bringing into discussion the social worker's mission.

\subsection{Lesson for the Social Work System and Professionals}

Research Question 3: What can be learnt about how to deal with the VUCA world of the COVID19 pandemic for the social work system and professionals in order to contribute to the development of burnout prevention programmes?

The qualitative analysis led to some core recommendations made by grass-root professionals and managers in the field of social work, derived from the experience and lessons learned during the beginning and middle phases of the pandemic (data were collected June-December 2020).The recommendations for the social work system can be summarised in several main topics:

- Social policy: to revisit existing social policy in our country, and elaborate strategies for the development of social services based on the current reality;

- Status of the social work profession: increased recognition of the value and contribution of social work ("the social worker is a very important actor in the development of the community and its protection"; "more intense promotion of social work services");

- Management: visionary, competent, devoted managers, prepared to act in extreme situations; clear procedures; bottom-up approach, not just top-down; working with the complete staff scheme; hiring only professional social workers, "invested in people, invested in professional training"; moral support;

- Emergency Commission: "to establish a functional commission and be prepared for emergency situations";

- Connectivity: developing more solid connections between communities and social services, statutory and private services;

- Budgeting: allocation of substantial funds in the social field; resources for prompt and efficient interventions in crisis situations; granting risk bonuses;

- Technologisation and digitisation: teleworking; increased use of technology, databases, online instruments ("Digitisation and computerisation of work procedures are the most wonderful things that have happened");

- Simplicity and flexibility: to simplify procedures (e.g., "to issue certificates for those who are incurable on a permanent basis. It is overwhelming for parents whose children have incurable diseases to come with their child every year for evaluation").

The core recommendations for social worker practitioners refer to:

- Social work mission: "even in the absence of a pandemic, they are the people on the front line";" the work as a social worker is very important in times of crisis and must remain connected in the middle of the action, put fears aside and act for others";

- Resilience: capacity to adapt rapidly to changes and learn to live with uncertainty ("uncertainty can characterise anything"); positive attitude ("nothing is unsolvable");

- Accepting human limits: "to learn first of all that we are human"; "we are human beings and we cannot help everyone; we do what we can";

- Self-care: "to take greater care of their health"; "to take care of their souls so that they can continue their work in social work"; managing one's own emotions and fears;

- Teamwork: to support each other, to share ideas and methods, to come together to find the best solutions;

- Ongoing training on topics such as: stress management, time management, teambuilding; methods of working remotely/on platforms with beneficiaries, electronic recording and transmission of data;

- Personal development courses;

- $\quad$ Supervision and peer-support (individual and group formats). 
To conclude in line with the voices of social workers: "everything starts from the allocated financial resources and from the competence and quality of the people in the field. If they don't love people, if they are not emotionally prepared to be empathetic, patient, and intuitive, it is better to choose something else".

\section{Discussion}

Research specific to the COVID-19 pandemic has focused in the first instance largely on medical professionals, which was obviously necessary. However, the psychosocial problems generated put pressure on the social work system [14], whose dominant mission is to help people in crisis situations and those at risk. This paper aimed to explore and understand the changes posed by the new COVID-19 pandemic to the field of social work and its impact on social workers in terms of job stress and burnout.

Our findings suggested that social workers perceived a high level of job stress $(\mathrm{M}=8.61, \mathrm{SD}=1.62)$ related to work during the pandemic. The first hypothesis stating that a high level of perceived job stress is associated with a high level of burnout for social workers iwas confirmed in relation to personal burnout $\left(\mathrm{r}_{\mathrm{s}}=0.452, p=0.000\right)$ and work-related burnout $\left(\mathrm{r}_{\mathrm{s}}=0.37, p=0.003\right)$. The two burnout scales are interrelated [42]. However, further investigations would be able to provide more understanding to the reciprocal influences of personal burnout during the pandemic and work-related burnout. We have to be aware that the pandemic has caused many different forms and layers of loss, both personal and professional, and social workers are not immune to confronting them [23]. In addition, the presence of fear is highlighted both for clients and social workers [4], the latter of whom having to deal with the needs and emotions of the most vulnerable groups of people while also dealing with their own needs and emotions raised in this very different and turbulent period of time.

Previous research carried out before the COVID-19 pandemic has shown that social work is a profession at high risk for developing the burnout syndrome $[44,45,47,48]$. For example, the study on burnout carried out by Kristensen and his colleagues (authors of the Copenhagen Burnout Inventory) positioned social workers in fifth place among the 15 jobs investigated; another study on Romanian social workers compared to psychologists, medical staff, and educators showed that social workers proved to be the professional category with the highest degree of burnout (both general and sub-types) [71]. However, results of this study evidenced an insignificant difference between the average scores for two of the burnout scales-personal burnout $(\mathrm{PB}=55.9)$ and work-related burnout $(\mathrm{WB}=52.5)$. Moreover, the scores are higher now than those reported by other authors before the pandemic $[42,50]$.

These results support the assumption that the COVID-19 pandemic poses a higher risks for social workers' well-being. We can argue that burnout is indeed a serious problem for social workers today, as $15.7 \%$ of the sample investigated $(\mathrm{N}=83)$ were affected by high to very high/severe levels of work-related burnout and a large upper middle group of nearly one half $(44.2 \%)$ scored in a range of medium level to high level of work-related burnout. Our results seem to be in line with other recent data [11], which indicate that nearly half of all child welfare workers from the US (46.4\%) demonstrate mild or severe peritraumatic distress that may lead to professional burnout. Our results on client-related burnout $(\mathrm{CB}=38.4)$ were not significantly different from the other studies $[42,50]$ and were in line with studies also reporting higher levels of work-related burnout than clientrelated [42,48,72]. We could argue that the philosophy of social work (helping vulnerable clients) means that the very core of social work lies in relationships with clients, presuming that this is a protective factor against the client-related burnout. Therefore, even in a period of major changes such as those related to physical distance and changes in the way we work with clients (e.g., digitalisation, physical distance) [5,17,22], the stress related to the client remains at a lower level, and organisational factors are the ones that have the biggest impact on the level of burnout. However, they seem to be the least studied, with most of the studies on burnout focusing on personality traits and to a smaller extent on organisational 
determinants, whereas the social and societal context of burnout is not taken into account systematically [73].

Quantitative results corroborated with qualitative data suggested that the stress and burnout of social workers during this period was primarily due to personal and organisational factors and less due to clients, or the particularities of working with different categories of beneficiaries or individual factors such as age, family status, seniority, experience as a social worker, academic degree, stage of competence, and professional position. We assume that a larger sample would have been more relevant to illustrate potential relationships between levels of burnout and sociodemographic variables or different fields of intervention in social work. Recent literature has suggested some areas of social work practice which have been more difficult during the pandemic [16,17,24,25].

Our second hypothesis derived from the job demands-job resources model (JD-R) [26] assuming that the social workers that perceived a high workload without organisational support have a higher score of work related burnout than those that perceived a high workload with organizational support was confirmed. Increased workload was mentioned by the largest number of social workers $(52.8 \%)$ as being among the main stressors, which is in line with other studies $[37,43,44,74]$. Qualitative data provides more understanding regarding the types of job resources they expected from the organisation, but were limited, similar to other studies: support from the management team $[43,48,74-76]$, supervisory support [48,75,77], recognition and reward [44], and availability of tools. High job demands and low resources are known to be the primary reasons for burnout [63,78].

Other job demands perceived as stressors identified in our study and found in other studies were: aligning to new rules and decisions at a national level $[9,44]$ associated with inconsistency, instability, ambiguity of decisions, sudden changes or even their absence or non-assumption at the managerial level [44,47], lack of clarity of working procedures [9,43], lack of direct contact with clients, communication and relational work $[17,23,34]$, the risk of being a carrier (asymptomatic) and contamination in two ways-both by the social worker and by the beneficiary [11,14], difficulties related to technology (absence of it or digital skills) [5,22], managing fears, and panic of beneficiaries [4]. It is important to mention the factor "the desire to help more than I could" but lacking sufficient material/financial resources was present in almost half of the social workers included in the study, an indicator of the social worker's mission, leading to potential issues of social justice [13,21]. The effects of job stress, as other studies show, are more related to the level of fatigue, feeling overwhelmed, and emotional and physical exhaustion [44,45,55,78]. However, $24.1 \%$ of social workers considered resignation and $33.7 \%$ professional reorientation, an aspect confirmed in the literature. A Romanian study found workplace stress was among the top reasons for considering leaving, raising awareness on the aspect of migration of qualified social workers [10]. A high turnover rate is one of the most prevalent consequences of burnout in relation to social workers $[37,46,73]$.

As emphasised in one study [11], the COVID-19 pandemic has created unprecedented challenges for our health and human services systems in serving our most vulnerable families, children, and youth. These challenges were conceptualised in our study using the attributes of the VUCA framework as they are experienced by social workers. Volatility was due to instability and unpredictability, sudden changes related to the workplace (teleworking or direct work; suspension of some services and staff redeployment; technical unemployment), work content (change of target group), and the way of providing social services (physical/social distancing, increased use of technology); uncertainty was caused by fear of both social workers [20] and clients [4], chaos, the leaders' unpredictable, incoherent decisions or the lack of them; complexity was due to interconnected factors such as limitations, physical distancing, use of technology and lack of devices or skills of many clients, fighting with bureaucracy, and impeded institutional interconnections; ambiguity was caused by the lack of clarity and understanding of the virus and its transmission (generating fear in both social workers and clients), inconsistency of decisions or information transmitted from official sources, and lack of clear methodologies and procedures to apply 
decisions. While most social workers perceived these changes as stressful, there were a significant number of professionals who scored below the medium/moderate levels of work-related burnout (14.5\% none to low burnout symptoms and $27.7 \%$ low to medium level). Qualitative data showed that they perceived these changes and challenges as opportunities, displaying resilience, being motivated and stimulated to find new, creative solutions to deal with the work environment and client problems. Grappling with uncertainty and complexity can strengthen social workers' adaptability and skills, producing strong and resilient practitioners for the future [19]. Among the job resources which could buffer the impact of job demands on strain [63], over half of the respondents mentioned colleague/co-worker support $[20,23,44,47]$ while fewer mentioned managerial and client support. More attention should be given to this group of social workers in future research to understand their job resources and resilience.

Some authors suggest a positive reading of the VUCA acronym as Vision, Understanding, Clarity, and Agility. Leadership in a VUCA environment is that proposed by Yarger: "to exercise influence over the volatility, manage the uncertainty, simplify the complexity, and resolve the ambiguity" while complying with policy frameworks [31]. In order to meet these requirements, starting from the voice of practitioners and managers who participated in the study, we formulate recommendations for social work policy, leaders / managers and social work practitioners.

\subsection{Implications for Social Work Policy and Management}

Social work policy, legislation, strategies, and guidelines should be informed to a greater extent bottom-up, by grass-root professionals, to be correlated and respond to both strategic and priority needs within the system. This study suggested improvements in the areas of: increasing the status of the profession by recognising the value and contribution of social work, especially during these highly turbulent times; granting risk bonuses; increasing the number of social workers to reduce the workload, which is the primary stress factor; allocating substantial resources for prompt and meaningful interventions; reducing bureaucracy and implementing clear and simplified procedures to reduce complexity; investment in technology and computerisation of the system; and work flexibility, including teleworking. When it comes to social work leaders and managers, the process of selection and promotion must be apolitical and based on advanced selection procedures. Development of job profiles built based on a social work organization's top performers profile and job analysis is recommended. The candidate profile should then be compared with the designed job profile. Leaders of a VUCA environment should be able to:

- Be visionary: it is not about forecasting the future, which is quite unpredictable in these times, but about creating future through action, identifying the key priorities that matter most, installing habits and routines at individual, group, or organisational levels, which can lead to ripple-like change [31,79], and identifying and keeping values to foster a sense of stability. The results of this study pointed to the competent, devoted, and bottom-up informed decision-making process: investment in human resources and a complete staff scheme to reduce workload; employees only with a social work degree proved to provide higher quality services than those with other degrees [74]; ongoing training programmes (work with trauma/collective trauma, social work during crises, stress/burnout management techniques, IT skills and platforms, time management, and team-building); the establishment of an emergency commission; and increased connectivity with other institutions and between the public and private sector.

- Be understanding: it requires openness, accountability, and willingness to tackle tough issues, listening and relationship skills, regular communication, mirroring the behaviour one wants to see, and giving trust to others [31]. Results of this study and literature showed the key role played by adequate, constant supervision and support $[43,46,75-77]$. Emotional support by both supervisors and co-workers is associated with lower levels of burnout, job stress, and mental health problems [37]. 
Ongoing staff support groups, physical or online-supervision [77], peer-support, and emotional support-are highly needed and recommended [14].

- Be clear: it is about direction, accountability to people, process accountability, discipline, and integrity [31]; it requires clear expectations and objectives and greater flexibility, both of them being among the issues mentioned by social workers. Less bureaucracy, simplified procedures within the statutory system, and increased digitalisation would decrease workload.

- Be agile: it is about withstanding difficulties by changing in a flexible and swift manner; agile leaders adapt quickly, are open and flexible to new approaches, and are learning and developing constantly from cause-effect analysis instead of being blocked by planned strategies.

Awareness of uncertainty, ongoing critical thinking, and constant negotiations are critical skills for approaching uncertainties [20]. The managerial challenge and responsibility is to create sustainable work conditions that facilitate a stable workforce and the provision of good social services [62]. Transformational leadership [63] is required in social services to embrace the challenges of the new era if social work should not come to an end [80].

\subsection{Implications for Social Work Practitioners}

Results of the study showed that personal exhaustion scores were the highest, close to work-related burnout. In addition to professional challenges, social work practitioners may be coping with personal challenges, such as home-schooling, caregiving, economic uncertainty, and the like that may impact their professional roles [11]. Literature on occupational stress and coping highlighted that the more proficient copers were most likely to have a clear self-care plan, participate in activities or hobbies, have a work-to-home transition plan [49], maintain a healthy physical state through regular exercise, a nutritional diet, and good sleep, and have a strong mental state intellectually, emotionally, and spiritually [81]. There is also a burgeoning "self-care" movement, which advocates taking a trauma-informed approach to dealing with stressors such as attending specialised training, being mindful or aware of one's responses to stressors, creating a self-care plan, and engaging in supervisor support. Trauma-informed care refers to the evidence-based practices for trauma, including understanding and recognising the effect that trauma exposure has on clients, as well as workers, and adequate knowledge and skill in responding to the effects of trauma exposure. Some research has found links between this type of self-care and decreased burnout [46,49]. Findings point to the importance of social workers to be proactive regarding their mental health status, prioritise self-care [20,23], and develop plans for work-life balance.

\section{Conclusions}

The world of work is constantly changing, and today, in the midst of the COVID-19 pandemic with case numbers rising, the only certainty is uncertainty. This study aimed, firstly, to assess the levels of job stress and burnout of social workers during the pandemic and understand their relationship with job demands and resources; secondly, to discuss the characteristics of the VUCA framework as reflected in the work and experienced by social workers; and thirdly, to highlight the voices of professionals with lessons learned and suggestions for policy makers, leaders, and social workers.

Transformations generated by the COVID-19 pandemic have changed the context and the process of intervention in the field of social work. Results of this study emphasised the presence of all the attributes of VUCA - volatility, uncertainty, complexity, and ambiguityin the social workers' daily activity, leading to a higher stress generated by organisational factors compared with the stress generated by the work with clients. Our results are in line with other studies that show that personal burnout and work-related burnout have higher values than client-related burnout. Social workers are a profession at risk of developing burnout which increased in severity during the pandemic when perceived job demands and stress factors were amplified while job resources were limited. Hence, a proportion of 
fifteen percent of the studied sample were already affected by high to very high/severe levels of work-related burnout, and a considerable proportion of almost half of the sample were impacted by medium to high levels of work-related burnout. A group of about forty percent scored below the medium levels of work-related burnout, and managed to handle stress factors in a healthy manner. If we agree that development of burnout is a dynamic process which may take different pathways [78,82], we agree that each social worker can navigate over time from one category to another, depending on the complex interplay of job demands and job resources, but also personal characteristics. Looking into the future, the upper middle group, which is the largest, may develop different pathways, either towards burnout or towards well-being. There is a need to implement programmes aimed at burnout prevention, which proved to be effective [83].

In order to meet the new challenges in the field of work, the social work leaders must discover, understand, and adapt to the VUCA environment-volatile, uncertain, complex, and ambiguous-developing vision, understanding, clarity, and agility, which would lower the pressure social workers are experiencing. On the other hand, social workers have to be proactive and develop strategies to care for their mental well-being. To conclude, results pointed to the importance of both organisational support and developing a self-care plan that helps to protect against job stress and burnout. Taking into consideration all the negative effects of the burnout syndrome, related to the well-being of the person, the clients, and the organisation, the efforts and costs of recovery interventions, burnout must be prevented rather than cured.

The innovative aspect of the study consisted of the application of the VUCA framework to the social work environment for its potential to bring a new understanding of the challenges encountered by leaders and practitioners during the COVID-19 pandemic and suggest ways to deal with them in order to prevent social worker burnout, integrating the voices of professionals and researchers (authors and social work educators). As suggested by The British Journal of Social Work [16], country-specific descriptions, reflections, and lessons learned on how to deal with these unprecedented times may make an international contribution.

\section{Limitations and Further Research}

There were several limitations to the study. The sample was relatively small, workload being one of the potential obstacles, as consistent efforts were made for data collection through collaboration with the main statutory organisations, the local social workers college, and NGO's network, while some questionnaires were also distributed in printed format. There are a disproportionate number of social workers in the public compared to the private sector, which does not allow for a more detailed comparison between the two groups of professionals and systems. The CBI-R scale was validated on Romanian medical staff and used in other Romanian studies on other professions [84], however not on social workers. Another limitation is related to the fact that, through data collected by us, we illustrated only the relationships between perceived workload and lack of organisational support at the general level. This project is ongoing and aims to further develop in several directions: to build an explanatory model for how the type of job demands combined with the type or quantity of job resources predict a high level of work-related burnout; to collect more data from the private sector to enable comparisons between social workers from the statutory and private work areas to understand if these different organisational settings influence levels of burnout; to expand research at the national level with support from the National College of Social Workers; and to explore how job resources and resiliencepromoting factors buffer against job demands and stressors and prevent burnout.

Supplementary Materials: The following are available online at https://www.mdpi.com/article/10 .3390/su13137109/s1, Table S1: Copenhagen Burnout Inventory (CBI-R). Scales, items and response frequencies, Table S2: T-test results: Perceived job stress level and system type, Table S3: T-test results: Burnout scales-Paired Differences Table S4: Chi-Square Tests: Level of work-related burnout, Table S5: The high workload perceived, organisational support, and level of work-related burnout. 
Author Contributions: Conceptualisation and project administration, G.D.; methodology, G.D., L.M.S.; software, L.M.S.;., investigation, G.D., M.-C.S.; resources, G.D., M.-C.S., writing-original draft preparation, G.D., M.-C.Ș., L.M.S.; writing-review and editing, G.D., M.-C.S,., L.M.S.;. All authors have read and agreed to the published version of the manuscript.

Funding: This research received no external funding. Publishing fees were covered by the Transilvania University of Brasov, Romania.

Institutional Review Board Statement: The study was conducted according to the guidelines of the Declaration of Helsinki, and approved by the Ethics Commission in social research of Transilvania University of Brasov, Romaia, number 21 of 27 July 2020.

Informed Consent Statement: Informed consent was obtained from all subjects involved in the study.

Data Availability Statement: Data available on request due to ethical restrictions.

Acknowledgments: The authors would like to bring thanks to the General Direction of Child Protection and Social Assistance of the county, the Social Work Direction and the College of Social Workers, local branch who disseminated the questionnaire to professionals and to the social workers, who took the time to fill it in online.

Conflicts of Interest: The authors declare no conflict of interest.

\section{References}

1. Severo, E.A.; De Guimarães, J.C.F.; Dellarmelin, M.L. Impact of the COVID-19 pandemic on environmental awareness, sustainable consumption and social responsibility: Evidence from generations in Brazil and Portugal. J. Clean. Prod. 2021, 286, 124947. [CrossRef] [PubMed]

2. Rupani, P.F.; Nilashi, M.; Abumalloh, R.A.; Asadi, S.; Samad, S.; Wang, S. Coronavirus pandemic (COVID-19) and its natural environmental impacts. Int. J. Environ. Sci. Technol. 2020, 17, 4655-4666. [CrossRef]

3. Dascalu, S. The Successes and Failures of the Initial COVID-19 Pandemic Response in Romania. Front. Public Health 2020, 8, 344. [CrossRef]

4. Runcan, R.; Runcan, P.L. Pandemia COVID-19 și Sentimentul de Teamă Resimțit în Sistemul de Asistență Socială din România. In Implicațiile Economice și Sociale ale Pandemiei COVID-19: Analize, Prognoze și Strategii de Atenuare a Consecințelor; Institutul Național de Cercetări Economice: Chișinău, Republic of Moldova, 2020; pp. 21-23.

5. Runcan, R. Social Work in Romania in the Time of the Covid-19 Pandemic: Strengths and Weaknesses. In NORDSCI International Conference; Conference Proceedings, Book 1, Volume 3; Saima Consult Ltd.: Sofia, Bulgaria, 2020; pp. $273-280$.

6. Redondo-Sama, G.; Matulic, V.; Munté-Pascual, A.; De Vicente, I. Social Work during the COVID-19 Crisis: Responding to Urgent Social Needs. Sustainability 2020, 12, 8595. [CrossRef]

7. Lazăr, F. Social Work and Welfare Policy in Romania: History and Current Challenges. In Visioni LatinoAmericane; EUT Edizioni Università di Trieste: Trieste, Italy, 2015; Volume 13.

8. Teșliuc, E.; Grigoraș, V.; Stănculescu, M. (Eds.) Studiu de Fundamentare Pentru Strategia Naţională Privind Incluziunea Socială Şi Reducerea Sărăciei 2015-2020; Bucharest World Bank: Bucharest, Romania, 2015.

9. Lazăr, F.; Mihai, A.; Gaba, D.; Ciocănel, A.; Rentea, G.; Munch, S. Romanian social workers facing the challenges of neo-liberalism. Eur. J. Soc. Work. 2019, 22, 326-337. [CrossRef]

10. Lazăr, F.; Lightfoot, E.; Iovu, M.B.; Dégi, L.C. Back from the Ashes of Communism: The Rebirth of the Social Work Profession in Romania. Br. J. Soc. Work. 2021, 51, 340-356. [CrossRef]

11. Miller, J.J.; Niu, C.; Moody, S. Child welfare workers and peritraumatic distress: The impact of COVID-19. Child. Youth Serv. Rev. 2020, 119, 105508. [CrossRef]

12. Fadel, L. Child Welfare Services and Caretakers Grapple with COVID-19 Effects. Available online: https://www.npr.org/2020/0 3/19/818221169/child-welfare-services-and-caretakers-grapple-with-covid-19-effects (accessed on 11 April 2021).

13. Banks, S.; Cai, T.; De Jonge, E.; Shears, J.; Shum, M.; Sobočan, A.M.; Strom, K.; Truell, R.; Úriz, M.J.; Weinberg, M. Practising ethically during COVID-19: Social work challenges and responses. Int. Soc. Work. 2020, 63, 569-583. [CrossRef]

14. Trancă, L.M. Challenges for Social Workers in Residential Centres Providing Social Services in Western Romania During the Covid-19 Pandemic. Soc. Work Rev. 2021, 20, 169-178.

15. Golightley, M.; Holloway, M. Social Work in the Time of the COVID-19 Pandemic: All in This Together? Br. J. Soc. Work. 2020, 50, 637-641. [CrossRef] [PubMed]

16. Golightley, M.; Holloway, M. Editorial: Unsung Heroes: Family and Home Care During Lock-Down. Br. J. Soc. Work. 2020, 50, 991-994. [CrossRef]

17. Golightley, M.; Holloway, M. Editorial: Unprecedented Times? Social Work and Society post-COVID-19. Br. J. Soc. Work. 2020, 50, 1297-1303. [CrossRef]

18. Segrave, M.; Maher, J. Coronavirus: Family Violence and Temporary Migration in the Time of COVID-19; Monash University-Lens: Clayton, Australia, 2020. 
19. Afrouz, R. Approaching uncertainty in social work education, a lesson from COVID-19 pandemic. Qual. Soc. Work. Res. Pr. 2021, 20,561-567. [CrossRef]

20. Hadar, K. Working in the department of social services in the shadow of the coronavirus. Qual. Soc. Work. Res. Pr. 2021, 20, 449-455. [CrossRef]

21. Starks, B. Humanity in social work pandemic pedagogy: Rejecting normalcy and embracing uncertainty. Qual. Soc. Work. Res. Pract. 2021, 20, 513-515. [CrossRef]

22. Wang, K.Y.-T.; Wen-Hui, T.; Chuang, T.-Y.; Lee, H.-J. Rethinking four social issues of the COVID-19 pandemic from social work perspectives. Asia Pac. J. Soc. Work. Dev. 2020, 31, 45-51. [CrossRef]

23. Aaslund, H. Compound loss, complex grief: Social work during a pandemic. Qual. Soc. Work. Res. Pr. 2021, 20, 123-125. [CrossRef]

24. Arnfjord, S. Greenland's emerging social conscience-Voluntary food delivery to people experiencing homelessness in Nuuk. Qual. Soc. Work. Res. Pr. 2021, 20, 433-438. [CrossRef]

25. Jones, R.K.; Westlake, D. Independent visiting with children in care during the pandemic: Disruptions and discoveries. Qual. Soc. Work. Res. Pr. 2021, 20, 383-389. [CrossRef]

26. Bakker, A.B.; Demerouti, E. Job demands-resources theory: Taking stock and looking forward. J. Occup. Health Psychol. 2017, 22, 273-285. [CrossRef]

27. Murugan, S.; Rajavel, S.; Aggarwal, A.K.; Singh, A. Volatility, Uncertainty, Complexity and Ambiguity (VUCA) in Context of the COVID-19 Pandemic: Challenges and Way Forward. Int. J. Health Syst. Implement. Res. 2020, 4, 10-16.

28. Korsakova, T.V. Higher Education in VUCA-World: New Metaphor of University. Eur. J. Interdiscip. Stud. 2019, 5, 31-35. [CrossRef]

29. Bennett, N.; Lemoine, G.J. What a difference a word makes: Understanding threats to performance in a VUCA world. Bus. Horizons 2014, 57, 311-317. [CrossRef]

30. Noda, Y. Socioeconomical transformation and mental health impact by the COVID-19's ultimate VUCA era: Toward the New Normal, the New Japan, and the New World. Asian J. Psychiatry 2020, 54, 102262. [CrossRef]

31. Codreanu, A. A VUCA Action Framework for a Vuca Environment. Leadership Challenges and Solutions. J. Def. Resour. Manag. 2016, 7, 31-38.

32. Caron, D. It's a Vuca World! Available online: https:/ / www.slideshare.net/dcaron/its-a-vuca-world-cips-cio-march-5-2009-draft (accessed on 11 April 2021).

33. Ioannidis, J.P.; Cripps, S.; Tanner, M.A. Forecasting for COVID-19 has Failed. Int. J. Forecast. 2020. [CrossRef]

34. Runcan, R. Social Work and "Social/ Physical Distancing". Rev. Asistenţă Soc. 2021, 20, 35-42.

35. Hart, P.M.; Cooper, C.L. Occupational Stress: Toward a More Integrated Framework. In Handbook of Industrial, Work and Organizational Psychology; Anderson, I.N., Ones, D.S., Sinangil, H.K., Viswesvaran, C., Eds.; SAGE Publications, Inc.: Thousand Oaks, CA, USA, 2001; Volume 2, pp. 93-114.

36. Hakanen, J.J.; Bakker, A.B.; Schaufeli, W.B. Burnout and work engagement among teachers. J. Sch. Psychol. 2006, 43, 495-513. [CrossRef]

37. Lloyd, C.; King, R.; Chenoweth, L. Social work, stress and burnout: A review. J. Ment. Health 2002, 11, 255-265. [CrossRef]

38. Freudenberger, H.J. Staff Burn-Out. J. Soc. Issues 1974, 30, 159-165. [CrossRef]

39. Maslach, C.; Jackson, S.E.; Schwab, R.L. Maslach Burnout Inventory: Manual; Consulting Psychologists Press: Palo Alto, CA, USA, 1986.

40. Grigorescu, S.; Cazan, A.-M.; Rogozea, L.; Grigorescu, D.O. Original targeted therapy for the management of the burnout syndrome in nurses: An innovative approach and a new opportunity in the context of predictive, preventive and personalized medicine. EPMA J. 2020, 11, 161-176. [CrossRef]

41. World Health Organization. Burn-Out an "Occupational Phenomenon": International Classification of Diseases. Available online: https: / / www.who.int/news/item/28-05-2019-burn-out-an-occupational-phenomenon-international-classification-ofdiseases (accessed on 11 April 2021).

42. Kristensen, T.S.; Borritz, M.; Villadsen, E.; Christensen, K.B. The Copenhagen Burnout Inventory: A new tool for the assessment of burnout. Work. Stress 2005, 19, 192-207. [CrossRef]

43. Yürür, S.; Sarikaya, M. The Effects of Workload, Role Ambiguity, and Social Support on Burnout among Social Workers in Turkey. Adm. Soc. Work. 2012, 36, 457-478. [CrossRef]

44. Marc, C.; Oșvat, C. Stress and Burnout among Social Workers. Soc. Work Rev. 2013, 3, 121-130.

45. Sánchez-Moreno, E.; Roldán, I.-N.D.L.F.; Gallardo-Peralta, L.P.; De Roda, A.B.L. Burnout, Informal Social Support and Psychological Distress among Social Workers. Br. J. Soc. Work. 2015, 45, 2368-2386. [CrossRef]

46. Salloum, A.; Kondrat, D.C.; Johnco, C.; Olson, K.R. The role of self-care on compassion satisfaction, burnout and secondary trauma among child welfare workers. Child. Youth Serv. Rev. 2015, 49, 54-61. [CrossRef]

47. Mák, K.; Fejes, É.; Pohl, M.; Kolonics, G.; Tóth, G.; Zádori, I.; Nemeskéri, Z.; Hesszenberger, D.; Fehér, G.; Tibold, A. A kiégés előfordulása szociális munkások körében. Orvosi Hetil. 2020, 161, 1884-1890. [CrossRef]

48. Hernandez, E. Mindfulness and Burnout among Social Workers. Available online: https://scholarworks.lib.csusb.edu/etd/1034 (accessed on 18 February 2021). 
49. Rienks, S.L. An exploration of child welfare caseworkers' experience of secondary trauma and strategies for coping. Child Abus. Negl. 2020, 110, 104355. [CrossRef]

50. Craiovan, P.M. Burnout, Depression and Quality of Life among the Romanian Employees Working in Non-governmental organizations. Procedia Soc. Behav. Sci. 2015, 187, 234-238. [CrossRef]

51. Raižienè, S.; Bakšytè, A. The relationship between the burnout of social service workers, social support and self-efficacy. Soc. Work 2010, 9, 119-126.

52. Kim, H.; Stoner, M. Burnout and Turnover Intention among Social Workers: Effects of Role Stress, Job Autonomy and Social Support. Adm. Soc. Work. 2008, 32, 5-25. [CrossRef]

53. Rupert, P.A.; Miller, A.O.; Dorociak, K.E. Preventing burnout: What does the research tell us? Prof. Psychol. Res. Pract. 2015, 46, 168-174. [CrossRef]

54. Johnson, S.; Cooper, C.; Cartwright, S.; Donald, I.; Taylor, P.; Millet, C. The experience of work-related stress across occupations. J. Manag. Psychol. 2005, 20, 178-187. [CrossRef]

55. Lizano, E.L. Examining the Impact of Job Burnout on the Health and Well-Being of Human Service Workers: A Systematic Review and Synthesis. Hum. Serv. Organ. Manag. Leadersh. Gov. 2015, 39, 167-181. [CrossRef]

56. Lesener, T.; Gusy, B.; Wolter, C. The job demands-resources model: A meta-analytic review of longitudinal studies. Work. Stress 2019, 33, 76-103. [CrossRef]

57. Bakker, A.B. A Job Demands-Resources Approach to Public Service Motivation. Public Adm. Rev. 2015, 75, 723-732. [CrossRef]

58. Demerouti, E.; Bakker, A.B.; Nachreiner, F.; Schaufeli, W.B. The job demands-resources model of burnout. J. Appl. Psychol. 2001, 86, 499-512. [CrossRef]

59. Bakker, A.B.; Demerouti, E. Job Demands-Resources Theory. In Wellbeing; Wiley: Hoboken, NJ, USA, 2014; Volume 3, pp. 1-28.

60. Chirico, F. Job Stress Models for Burnout Syndrome: A Review. Ann. dell'Istituto Super. Sanita 2016, 52, 443-456. [CrossRef]

61. Ravalier, J.M.; McFadden, P.; Boichat, C.; Clabburn, O.; Moriarty, J. Social Worker Well-being: A Large Mixed-Methods Study. Br. J. Soc. Work. 2021, 51, 297-317. [CrossRef]

62. Astvik, W.; Welander, J.; Larsson, R. Reasons for Staying: A Longitudinal Study of Work Conditions Predicting Social Workers' Willingness to Stay in Their Organisation. Br. J. Soc. Work. 2019, 50, 1382-1400. [CrossRef]

63. Schaufeli, W. Applying the Job Demands-Resources model. Organ. Dyn. 2017, 46, 120-132. [CrossRef]

64. Creswell, J.W.; Clark, V.L.P. Designing and Conducting Mixed Methods Research, 3rd ed.; SAGE Publications, Inc.: Los Angeles, CA, USA, 2017.

65. Bryanton, O.; Weeks, L.E. Informing the Development of Educational Programs to Support Older Adults in Retiring From Driving. Educ. Gerontol. 2014, 40, 756-766. [CrossRef]

66. Podsakoff, P.M.; MacKenzie, S.B.; Podsakoff, N.P. Sources of Method Bias in Social Science Research and Recommendations on How to Control It. Annu. Rev. Psychol. 2012, 63, 539-569. [CrossRef]

67. Wittink, M.N.; Barg, F.K.; Gallo, J.J. Unwritten Rules of Talking to Doctors About Depression: Integrating Qualitative and Quantitative Methods. Ann. Fam. Med. 2006, 4, 302-309. [CrossRef] [PubMed]

68. Weber, R. Basic Content Analysis; SAGE: London, UK, 1990.

69. Rn, B.D. Content analysis: Method, applications, and issues. Heal. Care Women Int. 1992, 13, 313-321. [CrossRef]

70. Hsieh, H.-F.; Shannon, S.E. Three approaches to qualitative content analysis. Qual. Health Res. 2005, 15, 1277-1288. [CrossRef]

71. Runcan, P.L. Aspects of Burnout among Professionals. Rev. Asistenta Soc. 2013, 3, 111-119.

72. Leake, R.; Rienks, S.; Obermann, A. A Deeper Look at Burnout in the Child Welfare Workforce. Hum. Serv. Organ. Manag. Leadersh. Gov. 2017, 41,1-11. [CrossRef]

73. Heinemann, L.V.; Heinemann, T. Burnout Research. SAGE Open 2017, 7. [CrossRef]

74. Strolin, J.S.; McCarthy, M.; Caringi, J. Causes and Effects of Child Welfare Workforce Turnover. J. Public Child Welf. 2006, 1, 29-52. [CrossRef]

75. Runcan, P.L.; Goian, C.; Laurentiu, T. The Socio-Communicational Style and the Need for Supervision of Professionals from the Social Services. Rev. Res. Soc. Interv. 2012, 37, 180-195.

76. Stoica, M.; Brate, A.T.; Bucuţă, M.; Dura, H.; Morar, S. The Association of Loneliness at the Workplace with Organisational Variables. Eur. J. Sci. Theol. 2014, 10, 101-112.

77. Oșvat, C.; Marc, C. Group Supervision in Social Work. A Model of Intervention for Practitioners. Soc. Work Rev. 2014, 1, 17-26.

78. Mäkikangas, A.; Leiter, M.P.; Kinnunen, U.; Feldt, T. Profiling development of burnout over eight years: Relation with job demands and resources. Eur. J. Work. Organ. Psychol. 2020. [CrossRef]

79. Johansen, B. Get There Early: Sensing the Future to Compete in the Present, 1st ed.; Berrett-Koehler Publishers: San Francisco, CA, USA, 2007.

80. Maylea, C. The end of social work. Br. J. Soc. Work. 2020, 51, 772-789. [CrossRef]

81. Grecu, A.; Brate, A.T.; Bucuţă, M.; Milcu, M.; Cernuşcă-Miţariu, M. The Role of Individual Differences as Predictors in the Process of Occupational Stress for Romanian Teachers. Eur. J. Sci. Theol. 2014, 10, 179-184.

82. Kim, H.; Ji, J.; Kao, D. Burnout and Physical Health among Social Workers: A Three-Year Longitudinal Study. Soc. Work. 2011, 56, 258-268. [CrossRef] 
83. Maricuţoiu, L.P.; Sava, F.; Butta, O. The effectiveness of controlled interventions on employees' burnout: A meta-analysis. J. Occup. Organ. Psychol. 2014, 89, 1-27. [CrossRef]

84. Tîru, L.G.; Opran, C. The Presence of Burnout among Employees from a Multinational Company in COVID19 Pandemic Context. Soc. Work Rev. 2021, 1, 135-147. 